Sven Cvek

Faculty of Humanities and Social Sciences

University of Zagreb

\title{
Digital Humanities between Technology and Labor
}

In this essay I offer a reflection on a conspicuous absence in digital humanities discourse. Engaging with the manifold ways in which the digital sphere shapes culture and society, the interests and methods of digital humanities appear indispensable in contemporary academia. However, it is my contention that digital humanities systematically omits dealing with the ways in which issues of technology converge with our labor in humanities today. Viewed in the context of an increasing adaptation of research and higher education to the market form, this disciplinary blind spot reveals technological instrumentality as a structuring principle of both digital humanities and its institutional setting, the "university of excellence."

Key words: digital humanities, university, technology, capitalism

In this text I want to reflect on the current popularity of digital humanitiesor what some have termed "the computational turn" in the humanities - by taking into account its relationship to issues of (digital) technology and (academic) labor. What follows will revolve around the following argument: A relatively recent disciplinary development in the US and European academia, the field of digital humanities cannot be thought of simply in terms of its often very relevant contributions to humanities research. Rather, the institutionalization of the new field, and its influence on existing disciplines, should also be understood as a symptom of the more general state of the humanities today. In its predominantly entrepreneurial, project-oriented approach and demand for technical knowledge, the digital humanities trend outlines the model practice for an increasingly market-oriented academia. This could be put another way, more polemically: while digital humanities focuses on the 
place of digital technology in relation to humanities research, it can easily neglect the more general relationship between technology and labor. This omission is the more striking when one has in mind the fact that digital humanities is often understood as a way out of a perceived crisis in the humanities. This crisis, which has to do with both shrinking material resources and shifting institutional terrain, is real. Although it unfolds in different ways in different cultural settings, its overall effects seem to imply the precarization and recomposition of academic labor. Instead of a fully elaborated argument about this process, the format of this paper allows only for a sketch of my own position and a commentary on what I consider a symptomatic blind spot in the practice of digital humanities.

My own interest in this subject comes not from within digital humanities, but from a concern for the ways in which technology is implicated in what I see as the progressive adaptation of the university to the market form. The peripheral position from which I am speaking-namely, that of a member of a "post-socialist" national academia undergoing integration into the global flows of capital and labor through the Bologna process-offers the privilege of a vantage point from which the capitalist logic of the encounter between the digital and the humanities can perhaps be more readily observed. In the Croatian case, the increased orientation of the university towards the market takes several directions: research is supposed to be as marketable as possible, where possible at all, and it is governed by competition for scarce resources. With the introduction of tuition fees where previously these did not exist, higher education is progressively losing its status as a public or common good. Along with these trends, in the process of integration of European research and higher education, the university is undergoing what some term "endogenous privatization." This term is used by economists to describe a situation in which there is no formal change in ownership; instead, the work process is "reorganized in line with capitalist discipline." Once exempt from such a logic, these critics argue, European universities are now reorganized 
according to the business model (Krašovec 81-82). ${ }^{1}$ This reorganization brings with it sometimes dramatic changes in the nature of scholarly work, but also in the composition of academic labor, as new, usually administrative positions are introduced, most often simply as an additional burden for the existing labor force. When the Bologna reform was introduced in Croatia, ${ }^{2}$ a series of changes swept the system of research and higher education, ranging from structural changes in financing to apparent technicalities regarding the evaluation of students, teachers, and researcher ; the administration of mobilities and exchange ; the maintenance of networking and partnership ; the management of projects, etc. All of these new or reformed moments in our academic life are inseparable from the technological (digital) infrastructure which was either adapted to or introduced in those spheres of work where it previously played a more marginal role. Old administrative tasks such as grading are now taking place online; new tasks of administering or coordinating various kinds of "mobilities" of teachers and students, or applying for research grants, are also taking place entirely through the Web. In other words, the presence of digital technology in the everyday life of Croatian academics has been brought to a new level in the process of a market-driven university reform. It is from this position that I ask the the following question: Does the field of digital humanities engage in any way with the institutional-technological nexus emerging from this conjuncture?

This question should lead us to a general consideration about digital

$1 \quad$ Ball and Youdell describe endogenous privatisation as involving "the importing of ideas, techniques and practices from the private sector in order to make the public sector more like businesses and more business-like" (9).

2 Croatia signed the Bologna Declaration in 2001, and the first generation of students enrolled in a reformed University of Zagreb in the fall of 2005 (Turković). Here, I understand the Bologna reform as an integral, operative part of the redefinition of education as a commodity now taking part in the "trade in educational services," as these are regulated by the General Agreement on Trade in Services (GATS). For an extended discussion of this topic, see Pereira. The current "liberalization" of higher education in post-socialist countries should not prevent us from recognizing historical continuities that complicate a too-easy notion of post-socialist transition. For an example of this kind of research, see Bacevic. 
humanities work. Digital humanities is a more recent and significantly expanded development of an older academic discipline called "humanities computing," which usually traces its beginnings back to 1949 and the first applications of computing to linguistic corpora. Most broadly, digital humanities today is about "using information technology to illuminate the human record, and bringing an understanding of the human record to bear on the development and use of information technology," as the 2004 Companion to Digital Humanities puts it (Schreibman et al.). In practice, digital humanities can include anything from the vast realm of "the digital," such as online publishing, the digitalization of archives, data visualization, or 3D modeling. The trend has touched the discipline of American Studies, too, with the American Studies Association organizing digital humanities panels at its annual conferences for several years now. In her remarks at the 2012 DH ASA panel, Lauren Klein complicates the usual story of the origins of the field-wherein the Italian Jesuit Roberto Busa collaborates with IBM to compile a lexical index of the works of Thomas Aquinas-by focusing on the work of the women operators of ENIAC, the programmers of the world's first computer in 1945. Introducing the problematic of "gendering and valuation of labor ... and the rise of the U.S. military-industrial complex" in the emerging field, Klein suggests that "the history of the digital humanities, in both its original and its expanded meanings, is also, necessarily, a history of gender, labor, and empire" (Klein). This is a welcome intervention in the more dominant understanding of digital humanities, in which technology can be reduced simply to its instrumental aspect. For instance, an exclusive emphasis on instrumental uses of technology in relation to humanities research is evident in a book entitled The American Literature Scholar in the Digital Age (2011), whose editors "hope to further encourage the profession to consider how digital media is affecting all aspects of our scholarship and to recognize that there will be increasing benefits and challenges in the use of technology in scholarship." They claim that "the digital medium, if utilized properly, can make insights more powerful, evidence more transparent, and communication more effective" (Earhart 2-3). (I will return later both to the issue of labor and the 
symptomatic use of notions such as "transparency" and "efficiency" in digital humanities discourse.)

The new (or "new") field has also been described as participating in yet another in an infinite series of scholarly turns, this time a computational one. David Berry thus speaks of digital humanities as an attempt to "take account of the plasticity of digital forms and the way in which they point toward a new way of working with representation and mediation, what might be called the digital 'folding' of reality, whereby one is able to approach culture in a radically new way" (1). The phrase "digital 'folding' of reality" strikes one as particularly suggestive, as it obviously need not be reserved for culture as an object of study. Berry explains the crucial act involved in such "folding": "a computer requires that everything is transformed from the continuous flow of our everyday reality into a grid of numbers that can be stored as a representation of reality which can then be manipulated using algorithms. These subtractive methods of understanding reality (episteme) produce new knowledges and methods for the control of reality (techne)" (2). The varied practices of digital humanities could do more to take into account the ways in which this new techne undergirds the processes transforming the everyday reality of academic labor. Despite the significant contributions of digital humanities to the humanities as a whole, the new field is reluctant to approach the scene of its institutionalization, or the academic context in which it takes place, in a way that would match the radical disposition it presumably takes towards culture.

This argument about the blind spot of digital humanities is not entirely original. Alan Liu, an early advocate of digital humanities in the United States, has posed the question about the place of "cultural criticism" in the field. His words are worth quoting at length, since they resonate with the problematic taken up here:

While digital humanists develop tools, data, and metadata critically ... rarely do they extend their critique to the full register of society, economics, politics, or culture. How the digital humanities advances, channels, or resists today's great postindustrial, neoliberal, corporate, and global flows of infor- 
mation-cum-capital is thus a question rarely heard in the digital humanities associations, conferences, journals, and projects. It is as if, when the order comes down from the funding agencies, university administrations, and other bodies mediating today's dominant socioeconomic and political beliefs, digital humanists just concentrate on pushing the "execute" button on projects that amass the most data for the greatest number, process that data most efficiently and flexibly..., and manage the whole through ever "smarter" standards, protocols, schema, templates, and databases uplifting Frederick Winslow Taylor's original scientific industrialism into ultraflexible postindustrial content management systems camouflaged as digital editions, libraries, and archives - all without pausing to reflect on the relation of the whole digital juggernaut to the new world order. (Liu 490-91)

While the problems listed by Liu are registered within the field, they remain rather marginal and demand a more critical sort of engagement. One way to begin doing this, as announced above, is by reflecting on the current position of digital humanities in academia, on the ways in which its rhetoric and its methodology are spilling over into other disciplinary fields, and on those aspects of the "digital 'folding' of reality" that have been left out of the new interdisciplinary practice.

The institutional history of the field helps illuminate its present-day status. In his informative critical history of the digital humanities, Patrik Svensson notes that "historically, and to some extent contemporarily, it would seem that a prototypical organizational form [for digital humanities] is a humanities computing unit or center affiliated with a school of liberal arts or humanities. Often such units provide service to the rest of the school and this rather instrumental function has typically been primary" (27, my emphasis). The inherent instrumentality of digital humanities might provide one answer to the question about the current popularity of the field, because that makes it, quite simply, marketable. It is no coincidence, then, that the field is gaining in prominence at a time when the humanities in general are undergoing difficult times; to this trend, digital humanities is supposed to provide an antidote. In 2010, Liu himself founded a digital humanities initiative, 
4Humanities, with the aim "to advocate for the humanities at a time when economic retrenchment has accelerated a long-term decline in the perceived value of the humanities" (Liu 490). In short, the digital humanities label has indeed proven to be a successful way to attract research funds. As Matthew Gold noted in 2012, "at a time when many academic institutions are facing austerity budgets, department closings, and staffing shortages, the digital humanities experienced a banner year that saw cluster hires at multiple universities, the establishment of new digital humanities centers and initiatives across the globe, and multimillion-dollar grants distributed by federal agencies and charitable foundations" (ix).

The language of digital humanities often reflects the mutual sympathy between the field and its funders. In it, we notice a recurrent use of some of the key terms of the current academic culture of projects. The "transparency" and "effectiveness" that the digital medium will presumably bring to the study of American literature, as mentioned above, is another case in point. In other digital humanities literature, this sort of rhetoric is even more explicit. In a volume entitled simply Digital Humanities, published by MIT press in 2012, the use of managerial jargon is completely normalized: the field is about “projects," "risk-taking," “competencies," "learning outcomes," "best practices," and so on. This particular volume actually openly embraces the spirit of academic enterprise, claiming to be a handbook for digital humanities project management (viii).

A certain lack of interest in the wider political and economic context of academic work and an insistent focus on matters of technique can be observed here. This inclination appears problematic if we consider the ways in which two of the self-professed fundamental values of digital humanitiesopenness and collaboration-become enmeshed in the technological-institutional frameworks of the corporate university. For example, in digital humanities, which prides itself on being "collaborative and committed to public knowledge" (Burdick vii), the idea of a commons of knowledge for which scholars have a special responsibility is certainly operative, particularly in the more successful examples of open-access publishing and the creation 
of public digital archives or databases. However, the hijacking of scholarly production by commercial interests, as evidenced for instance in the boycott of the academic publisher Elsevier (cf. Flood), or in the practice of charging authors for the costs of publication of their own articles in open-access journals, ${ }^{3}$ offers clear evidence that neither the technological potential of digital platforms nor the promise of open access exist outside the institutional and economic forces at play at any given moment. The other feature of digital humanities, its fundamentally collaborative character, also points to the same tension. From a European perspective, the collaborative requirements underpinning EU project funding and the institutional logic of academic culture more generally (with its demand for mobilities and focus on credit transfers) often turn collaboration into a purely formal matter of "partnerships," "exchanges," and "networks." The pervasive and increasingly naturalized metaphor of the network in particular should remind us that networks are also "the form of organization of the cooperative and the communicative relationships dictated by the immaterial paradigm of production" (Hardt and Negri, qtd. in Schaefer 213). This is certainly not to say that the ideals of openness and collaborative research should be abandoned, but that their meaning and social impact depends heavily on the political-economic and organizational frameworks within which they are practiced.

As I have already mentioned, the marketability of digital humanities comes as no surprise and is clearly related to the field's original instrumental function: an academic practice which offers expertise in data or content management must logically find its place in an economy geared towards the

3 This practice is unfortunately not limited to the so-called "predatory publishers," which will publish, in open-access form, more or less anything you are willing to pay for. SAGE Publications, a renowned publisher, has recently started SAGE Open, a peer-reviewed open-access journal that charges US\$99 for the "article processing charge" or "author publication fee" (taxes not included). According to the SAGE website, "Authors who do not have the means to cover the publication fee may request a waiver after acceptance" (SAGE Publications). 
flow and exchange of information. ${ }^{4}$ What remains more puzzling is the field's indifference towards the ways in which labor in the humanities in general is affected by the workings of the information economy, especially in light of the fact that universities are now positioned as suppliers of "educational services." Commenting on the Global Agreement on Trade in Services, the legal framework which also covers education, Ana Pereira notes the following: "Instead of providing a definition of 'services', GATS refers to the various ways in which services are supplied to delimit its coverage. Hence, the educational service sector covers any international trade in an educational sector provided through one of the four modes of supply: cross-border, consumption abroad, commercial presence and presence of natural person" (8). As Pereira herself remarks, this formalized understanding of trade in services, which emphasizes the circulation of educational services, is quite extensive. When digital technology is concerned, it is worth noting that "electronic delivery of services falls under the scope of GATS, as it can take place under any of the four modes of supply" (9). In fact, it could be argued that digital technology plays an ever more central role in this process of supply, since it provides the infrastructure for circulation (or trade) taking place. In this constellation, knowledge need not be mobilized for any ideological purpose, but merely for the purpose of circulation. The insistence on "mode of supply" or circulation in the legal and institutional framing of academic work is telling: this language points to the logic by which people-researchers, teachers, and students alike-become merely bearers of capital, which must circulate in the form of the allocation of project funds, of ECTS credits, or of mobility slots.

In order to further reflect on this problem, I would like to turn to Bill Readings' University in Ruins, a book about the transformations of academia

$4 \quad$ One of the more prominent digital humanities institutions, the Institute for Advanced Technology in the Humanities at the University of Virginia, sets as its goal "to explore and develop information technology as a tool for scholarly humanities research." Apart from that, it offers "consulting, programming, and data services to academic, cultural, non-profit, government, and business organizations" (About IATH, http://www.iath. virginia.edu/about_iath.html). 
in the context of capitalist globalization and the decline of the nation state "as the prime instance of the reproduction of capital" (3). After giving a panoramic view of the historical transformations of the institution of the university, Readings focuses on the contemporary notion of the university- the university of excellence-which is "either tied to transnational instances of government such as the European Union or functioning independently, by analogy with a transnational corporation" (3). The key legitimating notion in this development, excellence, is according to Readings referentially empty, and "functions to allow the University to understand itself solely in terms of the structure of corporate administration" (29). (Significantly, Readings claimed in 1997 that the effects of this process are felt not only in North America but also "in the states of the European Union and in Eastern Europe" [3].) In other descriptions of excellence, Readings insistently links the notion of excellence to the political-economic context in which the contemporary university functions, such as when he writes that "excellence responds very well to the needs of technological capitalism in the production and processing of information, in that it allows for the increasing integration of all activities into a generalized market, while permitting a large degree of flexibility and innovation at the local level" (32). "Technological capitalism" and the emphasis on information seem to bring his discussion of the contemporary university quite close to the interests of digital humanities. "As a non-referential unit of value entirely internal to the system," Readings writes, "excellence marks nothing more than the moment of technology's self-reflection. All that the system requires is for activity to take place, and the empty notion of excellence refers to nothing other than the optimal input/output ratio in matters of information" (39). His remark about the absolute requirement for "activity" emptied of any real content in the university of excellence gains a more concrete outline when situated in the context of the abstract description of "educational services," which are defined in GATS purely through their potential to circulate.

Of course, humanities work that deals with the problematic outlined above - the intersection of issues of higher education, digital technology, and 
capitalist economy - does exist, although it is usually not considered part of the digital humanities canon. David Noble's study of the effects of online education on the position of academic labor comes to mind, as well as the recent debates about the technological outsourcing of academic labor in the USA. ${ }^{5}$ In these writings, the relationship between technology and labor is taken up as the preeminent problem of the "university of excellence." Noble, who considers "the high-tech transformation of higher education" to be simply camouflage for its commercialization, writes that

With the commoditization of instruction, teachers as labor are drawn into a production process designed for the efficient creation of instructional commodities, and hence become subject to all the pressures that have befallen production workers in other industries undergoing rapid technological transformation from above. In this context faculty have much more in common with the historic plight of other skilled workers than they care to acknowledge.

Noble is certainly not alone in considering the implications of technological innovation for white-collar labor. In a similar vein, Simon Head has argued that

The emerging relationship between technology and work in the US economy of the late twentieth and early twenty-first centuries suggests that the corporate sector is relying on information technology both to simplify and accelerate the processes of business output, and so increase the output of labor, and to deskill labor, diminish its role, and so weaken its earning power. (13)

With the advent of "the university of excellence," these have become problems of the humanities, too. ${ }^{6}$ Significantly, the productive emphasis here

5 These have been well documented in The Chronicle of Higher Education: see Kolowich, Parry, Williams June.

6 Writing on the consequences of increased technological management of the work process in the service sector through "Computer Business Systems," Head comments on 
is on historical continuity when thinking about the position of technology in relations of production, rather than on a radical, technologically determined turn. $^{7}$

This problematic is not entirely absent from the field of digital humanities, although it is articulated in quite different terms than the ones offered by Noble or Head (namely, in terms of employability). If we look at examples, we see how issues of technology and labor do get registered in digital humanities, but only in order to be enveloped in terms sympathetic to the environment and discourse of the corporate university. One way in which digital humanities registers the impact of technology on labor is that it brings to light problems of institutionalization and valorization of new forms of work. One US commentator has remarked on the problem by drawing a parallel between work in digital humanities and consultancy (a parallel made quite explicit in the example from the University of Virginia, above). Echoing Svensson, Julia Flanders writes that

the digital humanities, as an institutional phenomenon, has evolved very substantially out of groups that were originally positioned as 'service' units and staffed by people with advanced degrees in the humanities: in other words,

the inherent contradictions of any attempt of such digital "folding of reality": "How can this regime of precise measurement and of panoptic managerial vision be transferred to a context where the objects of production are the treatment of sick patients, the transactions between teachers and pupils, or the decisions to hire and fire employees? The answer is that the structure and context of these activities must be expressed in a form that can be captured by the system, so that their digital representations can then be read and analyzed. But the limits of 'capturability' become apparent when one looks at transactions between human agents where attempts to impose 'capturability;' and with it the disciplines of CBSs [Computer Business Systems], distort the meaning of what is being done and leave the data thus generated highly vulnerable to GIGO — garbage in, garbage out." (Head 59) Head calls this misplaced managerial inclination "misindustrialization" and finds it at its most extreme precisely in academia (his example is the University of Oxford).

7 A thematic issue of Workplace: A Journal of Academic Labor entitled "Technology, Democracy, and Academic Labor” $(5.1,2002)$ offers more analyses in line with Noble's work. Of course, the relation of technology to labor is a classical Marxist topic. For a relevant discussion, see Caffentzis. 
people with substantial subject expertise who had gravitated toward a consulting role and found it congenial and intellectually inspiring. The research arising out of this domain, at its most rigorous and most characteristic, is on questions of method. (299, my emphasis)

Two points are important here. First, the institutionalization of digital humanities makes it possible for previously invisible forms of work to become recognized and valorized-especially the kind of work perceived to be somewhere between "purely technical" and "truly intellectual." Second, Flanders is aware that, in reality, consultancy-like work is becoming more and more central to academic labor as such. In fact, Flanders argues that, "just as critical theory came in the 1980s to occupy a position of metanarrative with respect to the traditional academic disciplines, so consultancy positions itself as a kind of metaknowledge, an expertise concerning the ways in which knowledge work is conducted" (298). ${ }^{8}$

The widening of the scope of humanities expertise, indicated by the "meta-" prefix, has really only one basic function: that of employability. William Pannapacker, in his article "No DH, No Interview," makes precisely this point:

$[\mathrm{T}]$ here are also more and more people who see $\mathrm{DH}$ as a means of coping with the lack of tenure-track positions and a means of increasing their options for alternative academic positions. DH offers transferable skills that can land them in administration, coding, grant writing, and project management if they are unable to find permanent academic posts. (Pannapacker)

Comments such as this one make it obvious how digital humanities appears in the academic spotlight at a moment when academic labor is caught in

8 This is not the only assessment of the digital humanities which compares it to critical theory. In his article in The Chronicle of Higher Education, "No DH, No Interview," William Pannapacker reports that "[Laura] Mandell [director of the Initiative for Digital Humanities, Media, and Culture at Texas A\&M University] said the digital humanities is partly a turn against the dominance of critical theory, which she called 'a PR failure and an intellectual failure: an excessive and unexamined lock-step discipline” (Pannapacker). 
the midst of important structural transformations. Starting from that premise, the emphasis on method in digital humanities that Flanders notes becomes also symptomatic of the increase in technical methods (and the requirement to know them) necessary for a growing need to manage administrative processes of the corporate university, all of which are unimaginable without the working knowledge of various digital platforms. The emergence and popularity of digital humanities thus points to the shift in the work of academicsunderstood as an instance of "cognitive labor"-from "brain work" to "chain work," or from "properly cognitive labor" to "mental labor of a purely applicative kind" (Berardi 79). Let me add here that this is not a complaint about the "degradation" of creative intellectual work-although that could certainly be a matter of debate, too. In reality, this shift can easily manifest itself as an increase in the work load for academic labor in total. The administrative-technical work is simply added to the existing pool of the work force and is distributed within existing resources (i.e., it necessarily represents an objective additional burden on a labor force already exposed to austerity measures and pressures of competition for funding). So it is not only that digital humanities, with its demand for technical expertise, makes it possible for previously unseen work to take an institutional form, as Flanders rightly notes; the institutionalization of digital humanities is itself evidence of the extent to which academic work is now "conducted as" a formal, technical matter, a matter of administering (or "coordinating") processes of various kinds (in the European case: mobility, exchange, efficiency, or productivity).

This structural moment remains largely unproblematic in the mainstream of digital humanities. Perhaps this is unremarkable, since the technicization of research and higher education appears as a condition for the establishment of digital humanities as a discipline. Still, it is well worth reflecting on, as it speaks to wider, systemic shifts that are occurring in academia in general. 


\section{WORKS CITED}

Ball, Stephen J. and Deborah Youdell. Hidden Privatisation in Public Education.

Education International, 2008. Sept. 1, 2014. <http://download.ei-ie.org/docs/

IRISDocuments/Research\%20Website\%20Documents/2009-00034-01-E.pdf>.

Bacevic, Jana. “(Education for) work sets you free: 'employability' and higher education in

former Yugoslavia and its successor states." European Journal of Higher Education 4.3 (2014): 281-96.

Berardi, Franco Bifo. The Soul at Work: From Alienation to Autonomy. Place: Semiotext(e), 2009.

Burdick, Anne, et al. Digital_Humanities. Cambridge, Mass. \& London: The MIT P, 2012.

Caffentzis, George. In Letters of Blood and Fire: Work, Machines, and the Crisis of Capitalism.

PM Press: Oakland, 2013.

Flanders, Julia. “Time, Labor, and 'Alternate Careers' in Digital Humanities Knowledge Work." Debates in the Digital Humanities. Ed. Matthew K. Gold. Minneapolis and London: U of Minnesota P, 2012. 292-308.

Flood, Alison. "Scientists sign petition to boycott academic publisher Elsevier." The Guardian, February 2, 2012. Sept. 1, 2014. <http://www.theguardian.com/ science/2012/feb/02/academics-boycott-publisher-elsevier $>$.

Gold, Matthew K. “The Digital Humanities Moment." Debates in the Digital Humanities. Ed. Matthew K. Gold. Minneapolis and London: U of Minnesota P, 2012: ix-xvi.

Head, Simon. Mindless: Why Smarter Machines are Making Dumber Humans. New York: Basic Books, 2014.

Klein, Lauren F. “Digital Origin Stories.” Remarks at the American Studies and Digital Humanities 2012 Roundtable. Lauren F. Klein Website. Sept. 1, 2014. <http:// lklein.com/2012/11/digital-origin-stories/>.

Kolowich, Steve. "Outsourced Lectures Raise Concerns About Academic Freedom." The Chronicle of Higher Education, May 28, 2013. Sept. 1, 2014. <http://chronicle.com/ article/Outsourced-Lectures-Raise/139471/>.

Krašovec, Primož. "Rad u nauci i kulturi.” U borbi za javno dobro: analize, strategije, perspektive. Eds. Darko Vesić et al. Beograd: Centar za politike emancipacije, 2012. Liu, Alan. "Where Is Cultural Criticism in the Digital Humanities?" Debates in the Digital Humanities. Ed. Matthew K. Gold. Minneapolis and London: Uof Minnesota P, 
2012. 490-510.

Noble, David F. "Digital Diploma Mills: The Automation of Higher Education." Monthly Review 49.9 (1998). Sept. 1, 2014. <http://monthlyreview.org/1998/02/01/ digital-diploma-mills/>.

Pannapacker, William. “'No DH, No Interview”' The Chronicle of Higher Education, July 22, 2012. Sept. 1, 2014. <http://chronicle.com/article/No-DH-NoInterview/132959/>.

Parry, Marc. "Outsourced Ed: Colleges Hire Companies to Build Their Online Courses." The Chronicle of Higher Education, July 18, 2010. Sept. 1, 2014. <http://chronicle. com/article/Outsourced-Ed-Colleges-Hire/66309/>.

Pereira, Ana Cristina Paulo. “The Liberalization of Education under the WTO Services Agreement (GATS): A Threat To Public Educational Policy?” Ética e Filosofia Política 2.11 (2009).

SAGE Publications. "Open Access FAQ." SAGE Publishing. Sept. 1, 2014. <http://www. sagepub.com/oa/oafaq.cp>.

Schäfer-Wünsche, Elisabeth. "Work and Net-Work: Reflections on a Global Metaphor." American Studies/Shifting Gears. Eds. Birte Christ et al. Heidelberg: Universitätsverlag Winter, 2010: 201-21.

Schreibman, Susan, Ray Siemens, John Unsworth, eds. A Companion to Digital Humanities. Oxford: Blackwell, 2004. Sept. 1, 2014. <http://www.digitalhumanities.org/ companion/>.

Svensson, Patrik. "Humanities Computing as Digital Humanities." Digital Humanities Quarterly 3.3. (2009). Sept. 1, 2014. <http://www.digitalhumanities.org/dhq/ $\mathrm{vol} / 3 / 3 / 000065 / 000065 . h t m l>$.

Turković, Vera. "Bolonjski proces - put prema zajedničkom europskom visokoobrazovnom prostoru." University of Zagreb. Sept. 1, 2014. <http://www.unizg.hr/studiji-istudiranje/cjelozivotno-obrazovanje-i-usavrsavanje/podrska-nastavnicima/ucenjei-poucavanje-u-visokom-obrazovanju-upravo/bolonjski-proces/>.

Williams June, Audrey. “Some Papers Are Uploaded to Bangalore to Be Graded.” The Chronicle of Higher Education, April 4, 2010. Sept. 1, 2014. <http://chronicle.com/ article/Outsourced-Grading-Comes-to/64954/>. 